\title{
A Systematic Review of Interactive Computer-assisted Technology in Diabetes Care Interactive Information Technology in Diabetes Care
}

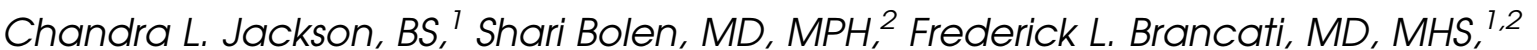 \\ Marian L. Batts-Turner, MSN, RN, CDE, ${ }^{2}$ Tiffany L. Gary, PhD ${ }^{7}$ \\ 'Department of Epidemiology, The Johns Hopkins Medical Institutions, Baltimore, MD, USA; ${ }^{2}$ Department of Medicine, The Johns Hopkins \\ Medical Institutions, Baltimore, MD, USA.
}

\begin{abstract}
BACKGROUND: Excellent diabetes care and self-management depends heavily on the flow of timely, accurate information to patients and providers. Recent developments in information technology (IT) may, therefore, hold great promise.
\end{abstract}

OBJECTIVE: To determine, in a systematic review, how emerging interactive IT has been used to enhance care for adults with type 2 diabetes.

METHOD: Eligible studies were randomized controlled trials (RCTs) and observational studies (both before-after designs and post-intervention assessments) focused on computer-assisted interactive IT that included $\geq 10$ adults with diabetes ( $\geq 50 \%$ type 2 ) and reported in English. We searched 4 electronic databases (up to 2003) using terms for diabetes and technology, reviewed bibliographies, and handsearched Diabetes Care (January 1990 to February 2004). Two reviewers independently selected articles and worked serially on data extraction with adjudication of discrepancies by consensus.

RESULTS: There were 26 studies (27 reports): internet ( $n=6$; 3 RCTs), telephone ( $n=7 ; 4$ RCTs), and computer-assisted integration of clinical information ( $n=13,7$ RCTs). The median (range) sample size was 165 (28 to 6,469 participants) for patients and 37 (15 to 67) for providers; the median duration was 6 ( 1 to 29) months. Ethnic minorities or underserved populations were described in only 8 studies. Six of 14 interventions demonstrated moderate to large significant declines in hemoglobin Alc levels compared with controls. Most studies reported overall positive results and found that IT-based interventions improved health care utilization, behaviors, attitudes, knowledge, and skills.

CONCLUSIONS: There is growing evidence that emerging IT may improve diabetes care. Future research should characterize benefits in the long term ( $>1$ year), establish methods to evaluate clinical outcomes, and determine the cost-effectiveness of using IT.

KEY WORDS: type 2 diabetes; information technology; computer; internet; self-management; clinical management; interactive; systematic review.

DOI: $10.1111 /$ j. 1525-1497.2005.00310.x

J GEN INTERN MED 2006; 21:105-110.

$\mathrm{T}$ ight control of blood glucose to either prevent or delay the progression of diabetes-related complications relies heavily on patient behavior modification and proper guidance/education from health care professionals. ${ }^{1}$ Information technology (IT), such as the computer, internet, multimedia, and other forms of electronic communication, holds great

The authors have no conflicts of interest to report.

The results were presented in part at the 64th Scientific Sessions of the American Diabetes Association, Orlando, FL, June 2004.

Address correspondence and requests for reprint to Dr. Gary: 614 North Wolfe Street, Rm E6531, Baltimore, MD 21205 (e-mail: tgary@ jhsph.edu). promise to influence diabetes care positively. Information technology provides an avenue for the rapid and easy dissemination of information to patients and clinicians as well as allows interactive communication between the patients and their health care provider teams. ${ }^{2}$ Despite the well-recognized potential of IT in health care, there has been little systematic evaluation of its present impact on the health care system. ${ }^{3}$

Several reviews have evaluated various IT interventions in type 1 diabetes care. Balas et al. ${ }^{4}$ evaluated computerized interventions to enhance diabetes management and reported positive outcomes for $12(80 \%)$ of the 15 trials, including improved hemoglobin Alc (HbAlc), blood glucose, and hypoglycemic events. Another review, conducted by the same author, evaluated 40 computer-assisted interventions and concluded that the majority showed significant improvements in glycated hemoglobin, blood glucose, guideline compliance, and reductions in hypoglycemic events and insulin doses. ${ }^{5}$ Glasgow and Bull $^{6}$ discussed the strengths and limitations of various technologies used to augment diabetes self-management education. Although not a formal systematic review, the article suggested that technology should help diabetes educators reach and support more people, and that health behaviors seemed to be more positively affected than biological outcomes.

Although the conclusions drawn from these articles are relevant, they evaluated mainly type 1 diabetes and the objectives of the reviews were limited. ${ }^{4-6}$ Both review articles focused solely on the use of IT for diabetes self-management without considering how IT would be incorporated into clinical practice ${ }^{5,6}$ Additionally, no reviews to date have reported ethnic minority participation rates or costs of IT interventions. Therefore, the goals of this systematic review were to: (1) provide an up-to-date assessment of the literature, (2) summarize the effects of interactive IT on several health care and clinical outcomes in type 2 diabetes samples, (3) assess the inclusion of ethnic minority populations, and (4) report costs associated with the interventions.

\section{METHODS}

\section{Eligibility Criteria}

Eligible studies were published randomized controlled trials (RCTs) or observational studies (nonRCTs, pre-post studies, and post-only studies) that implemented interactive

Manuscript received January 16, 2005

Initial editorial decision September 9, 2005

Final acceptance September 19, 2005 
technology as the main component of an intervention for diabetes care (all forms of IT were computer assisted). The review was limited to interactive interventions because of their potential to impact diabetes care by prompting action from the provider and/or patient. Eligible studies were published in English and studied $\geq 10$ adults ( $\geq 18$ years old) with diabetes, of whom $\geq 50 \%$ had type 2 diabetes.

\section{Search Strategy}

Published studies were identified by searching the electronic databases PubMed, PsycINFO, CINAHL, and Cochrane Library through 2003. The following keywords were used for each database: diabetes or noninsulin-dependent diabetes AND internet, internet-based, electronic, intervention, RCT, therapy, education, programs, techniques, impact of, and behavior. The search was limited to human subjects and the English language in the PubMed database. Additional strategies included searching bibliographies of eligible studies, a handsearch of the journal Diabetes Care from January 1990 to February 2004, and a related articles search in the PubMed database during the abstract review.

\section{Data Abstraction}

Titles and abstracts were independently reviewed by 2 investigators and if eligible, full articles were then abstracted by serial review. One investigator completed the standardized data abstraction form and a second investigator reviewed it for accuracy and completeness. If at any time both investigators could not resolve differences (i.e., eligibility criteria, interpretation of results), conflicts were adjudicated by a third investigator.

\section{Data Synthesis}

Because of the heterogeneity of the studies and the small number of articles in each category, we did not conduct a metaanalysis. Rather, we summarized the studies qualitatively, noting the outcome data in tables.

\section{RESULTS}

\section{Search Strategy}

Figure 1 describes the search outcomes. We found 27 eligible articles, which described 26 interventions ( 2 articles described 1 intervention). ${ }^{7,8}$

\section{Description of Study Characteristics}

Table 1 describes the included studies. Publication dates ranged from 1984 to 2003 (16 articles published in the last 3 years). The median age (range) for study participants was 59 (43 to 70), the median percentage for male participants was $47 \%$ (23\% to $95 \%$ ), and $86 \%$ (50\% to $100 \%$ ) for type 2 diabetes patients. The median sample size was $165(28$ to 6,469$)$ for patients and 37 (15 to 67 ) for providers. The median intervention duration and follow-up time period was 6 ( 1 to 29 ) months.

Eight studies reported inclusion of ethnic minorities (see Table 1 ), in which the median was $39 \%$ (5\% to $74 \%$ ). ${ }^{7,9-15}$ One study reported a population of $11 \%$ Asian Pacific Islanders. ${ }^{14}$ Of the 8 studies, 1 focused exclusively on Hispanics ${ }^{9}$ and 1 predominantly on African Americans (86\%). ${ }^{12}$

\section{Description of Intervention Characteristics}

In general, the studies sought to evaluate the effectiveness of technology-enabled programs to improve diabetes education, clinical outcomes, patients' perceived quality of life and support, as well as patient and provider processes of care (visits, testing, and documentation of adherence).

Articles were placed into 3 categories based on the main focus of the IT intervention: internet, telephone, and computer-assisted integration of clinical information. The studies in the internet category used interactive web technology to enhance patient self-management and clinical management by providing diabetes education and feedback of resulting data. Articles in the telephone category used interactive, automated telephone calls and telemedicine to enhance patient self-management through self-care education calls and feedback of

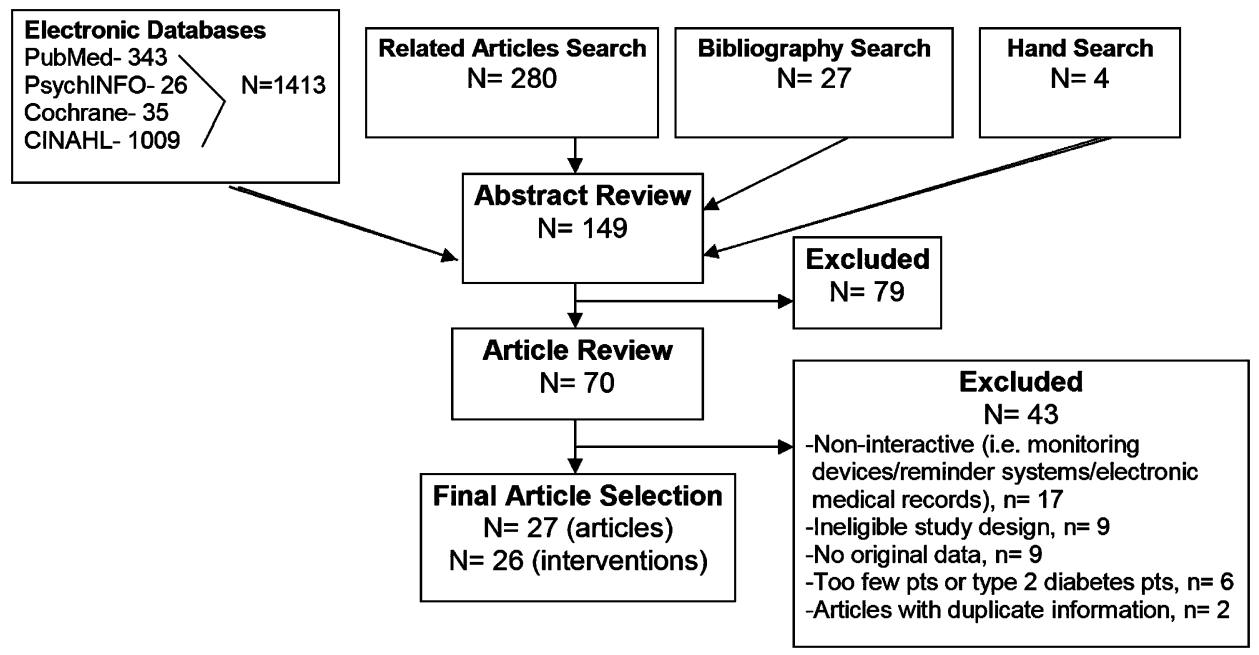

* N's indicate number of articles at each point

FIGURE 1. Summary of the literature search and review process. 
Table 1. Summary of Study Characteristics, $n=26$

\begin{tabular}{|c|c|c|c|c|c|c|c|c|c|c|c|}
\hline Article Category & $\begin{array}{l}\text { First } \\
\text { Author }\end{array}$ & $\begin{array}{c}\text { Year of } \\
\text { Publication }\end{array}$ & $\begin{array}{l}\text { Study } \\
\text { Design }\end{array}$ & Setting & $\begin{array}{l}\text { Mean } \\
\text { Age }\end{array}$ & $\begin{array}{c}\% \\
\text { Men }\end{array}$ & $\begin{array}{l}\text { Follow-Up } \\
\text { (mo) }\end{array}$ & $\begin{array}{c}\text { Target } \\
\text { Population }\end{array}$ & $N$ & $\begin{array}{l}\text { \% Min. } \\
\text { Pop. }\end{array}$ & $\begin{array}{l}\text { Decline in } \\
\text { HbAlc }\end{array}$ \\
\hline \multirow{6}{*}{$\begin{array}{l}\text { Internet-assisted } \\
\text { education }\end{array}$} & Barrera & 2002 & RCT & Web-based & 59 & 47 & 3 & Patient & 160 & NR & NR \\
\hline & Glasgow & 2003 & $\mathrm{RCT}$ & Web-based & 59 & 47 & 12 & Patient & 320 & NR & Small \\
\hline & McKay & 2001 & $\mathrm{RCT}$ & Web-based & 52 & 47 & 2 & Patient & 78 & 18 & NR \\
\hline & McKay & 1998 & Postonly & Web-based & 43 & 66 & 2.5 & Patient & 111 & NR & NR \\
\hline & Rushakoff & 2003 & Postonly & $\begin{array}{l}\text { Web-based/ } \\
\text { tech. }\end{array}$ & NR & NR & 6 & Provider & NR & NR & NR \\
\hline & Trikic & 2001 & $\begin{array}{l}\text { Pre-Post } \\
\text { test }\end{array}$ & Nursing School & NR & NR & 18 & $\begin{array}{l}\text { Nursing } \\
\text { students }\end{array}$ & NR & NR & NR \\
\hline \multirow[t]{5}{*}{$\begin{array}{l}\text { Telephone-automated } \\
\text { calls }\end{array}$} & Albisser & 1996 & $\mathrm{CCT}$ & Clinic & NR & NR & 12 & $\begin{array}{l}\text { Provider, } \\
\text { patient }\end{array}$ & 204 & NR & Large $^{\dagger}$ \\
\hline & Piette & 2001 & $\mathrm{RCT}$ & $\begin{array}{l}\text { Clinic/ } \\
\text { telephone }\end{array}$ & 61 & NR & 12 & $\begin{array}{l}\text { Provider, } \\
\text { patient }\end{array}$ & 272 & 40 & Small \\
\hline & Piette & 1997 & Postonly & Clinic & NR & 95 & 1 & $\begin{array}{l}\text { Provider, } \\
\text { patient }\end{array}$ & 65 & 39 & NR \\
\hline & Piette* & 2000 & $\mathrm{RCT}$ & Clinic & 55 & 27 & 12 & Patient & 248 & 74 & Moderate \\
\hline & Meneghini & 1998 & $\begin{array}{l}\text { Pre-Post } \\
\text { test }\end{array}$ & Clinic & NR & NR & 12 & $\begin{array}{l}\text { Provider, } \\
\text { patient }\end{array}$ & 184 & NR & Moderate $^{\dagger}$ \\
\hline \multirow[t]{2}{*}{ Telemedicine } & Izquierdo & 2003 & $\mathrm{RCT}$ & $\begin{array}{l}\text { Clinic/video- } \\
\text { con. }\end{array}$ & 58 & 46 & 6 & Patient & 46 & 5 & Moderate \\
\hline & Whitlock & 2000 & RCT & Clinic & 63 & 61 & 3 & $\begin{array}{l}\text { Provider, } \\
\text { patient }\end{array}$ & 28 & NR & Large $^{\dagger}$ \\
\hline \multirow{8}{*}{$\begin{array}{l}\text { Computer-assisted } \\
\text { integration of clinical } \\
\text { information-CAL }\end{array}$} & Albisser & 2001 & CCT & Clinic & 58 & 51 & 12 & Patient & 978 & NR & Large $^{\dagger}$ \\
\hline & Farrant & $\begin{array}{l}2001 \\
1984\end{array}$ & Postonly & Clinic & NR & $\begin{array}{l}51 \\
\text { NR }\end{array}$ & $\begin{array}{l}12 \\
\text { NR }\end{array}$ & Patient & 92 & NR & NR \\
\hline & Glasgow & 2000 & $\mathrm{RCT}$ & Clinic & 60 & 44 & 6 & Patient & 320 & 10 & Small \\
\hline & Glasgow & 1996 & RCT & Clinic & 62 & NR & 3 & $\begin{array}{l}\text { Provider, } \\
\text { patient }\end{array}$ & 206 & NR & Small \\
\hline & Levetan & 2002 & RCT & Clinic & 59 & 33 & 6 & $\begin{array}{l}\text { Provider, } \\
\text { patient }\end{array}$ & 150 & 86 & Large $^{\dagger}$ \\
\hline & Lo & 1996 & $\mathrm{RCT}$ & Clinic & 52 & 36 & 3 & Patient & 36 & NR & $\mathrm{UD}^{\dagger}$ \\
\hline & Wheeler & 1985 & $\mathrm{RCT}$ & Clinic & 53 & 31 & 1 & Patient & 32 & NR & NR \\
\hline & Wise & 1986 & RCT & Clinic & 50 & NR & 6 & Patient & 174 & NR & Moderate \\
\hline \multirow{3}{*}{$\begin{array}{l}\text { Electronic disease } \\
\text { management system }\end{array}$} & Montori & 2002 & CCT & Clinic & 70 & 42 & 24 & Provider & 200 & NR & UD \\
\hline & Selecky & 2001 & $\begin{array}{l}\text { Pre-Post } \\
\text { test }\end{array}$ & Web-based & NR & NR & 12 & $\begin{array}{l}\text { Provider, } \\
\text { patient }\end{array}$ & 646 & NR & NR \\
\hline & Smith & 1998 & Postonly & Clinic & 61 & 55 & 12 & Provider & 82 & NR & NR \\
\hline $\begin{array}{l}\text { Personal database } \\
\text { manager }\end{array}$ & Cherry & 2002 & $\begin{array}{l}\text { Pre-Post } \\
\text { test }\end{array}$ & Web-based & 53 & 23 & 12 & $\begin{array}{l}\text { Provider, } \\
\text { patient }\end{array}$ & 169 & 100 & NR \\
\hline $\begin{array}{l}\text { Computer-assisted } \\
\text { flowsheets }\end{array}$ & Lobach & 1994 & $\mathrm{RCT}$ & Clinic & NR & NR & 5 & Provider & NR & NR & NR \\
\hline
\end{tabular}

*2 articles, 1 intervention.

${ }^{\dagger} \mathrm{P}<.05$.

26 interventions $/ 27$ articles.

Magnitude of decline from baseline to follow-up in HbAlc or GHb in intervention group: <0.5\%, small; 0.5\% to $1 \%$, moderate; > 1\%, large.

RCT, randomized-controlled trial; CCT, controlled clinical trial; tech., technology; con., conference; hosp., hospital; off, office; oth., other; NR, not reported; N, sample size; min., minority; pop, population; UND, unable to determine; CAL, computer-assisted learning; HbA1c, hemoglobin A1c; GHb, glycohemoglobin.

self-monitored information to the provider. Articles in the computer-assisted integration of clinical information category consisted of computerized patient education and interventions that integrated electronic practice guidelines, reminder systems, and feedback of clinical data to enhance both self and clinical management. All 3 categories included technology focusing on self and/or clinical management and differed mainly by their mode of delivery.

\section{Clinical Outcomes}

Studies measured clinical outcomes such as HbAlc levels, body weight, blood pressure, microalbumin, creatinine, lipids, depression, and hematocrit values. Six of 14 studies demonstrated significant declines in HbAlc levels among intervention groups ${ }^{12,16-20}$ (Table 1). One intervention from the internet category measured $\mathrm{HbAlc}$ and showed a small, nonsignificant decline. ${ }^{21}$ Interventions in the telephone category showed moderate or large declines although only three of the
16 studies were statistically significant. Studies in the computer-assisted integration of clinical information category had mixed results.

Studies that reported outcome data on change in body weight, ${ }^{10-12,16,17,20,22}$ blood pressure, ${ }^{11,12,23,24}$ microalbumin, ${ }^{12,20,24}$ and creatinine ${ }^{20}$ generally found no significant difference between intervention and control groups. Studies that evaluated lipids ${ }^{10-12,20,21,23-25}$ and depression ${ }^{13,21}$ found both significant and nonsignificant decreases.

\section{Health Care Utilization}

A summary of health care utilization outcomes $(n=8)$ is shown in Table 2. Although there were mixed results regarding hospitalizations, ${ }^{9,16}$ a number of studies reported an increase in foot exams ${ }^{7,15,23,24}$ and HbAlc tests, ${ }^{23,24,26}$ as well as favorable outcomes with regard to primary care visits. ${ }^{7,9,15,16,19}$ The 2 studies that reported decreases in primary care visits were both associated with favorable outcomes. One study used a 
Table 2. Change in Diabetes Health Care Utilization Among Intervention Groups Compared with Control, $n=8$

\begin{tabular}{|c|c|c|c|c|c|}
\hline Content category & $\begin{array}{l}\text { Hospitalizations } \\
\quad(n=3)\end{array}$ & $\begin{array}{l}\text { Primary Care Visits } \\
\qquad(n=5)\end{array}$ & $\begin{array}{l}\text { Foot Exams } \\
\qquad(n=4)\end{array}$ & $\begin{array}{l}\text { Eye Exams } \\
\quad(n=5)\end{array}$ & $\begin{array}{l}\text { HbAlc Test } \\
\quad(n=4)\end{array}$ \\
\hline \multicolumn{6}{|l|}{ Telephone } \\
\hline Albisser (1996) & - & $\uparrow$ & - & - & - \\
\hline Meneghini (1998) & - & $\downarrow * \dagger$ & - & - & - \\
\hline Piette (2000) & $\mathrm{NC}$ & $\mathrm{NC}$ & $\mathrm{NC}$ & - & - \\
\hline Piette (2001) & - & $\uparrow$ & $\uparrow$ & $\mathrm{NC}$ & - \\
\hline Montori (2002) & - & - & - & - & $\uparrow$ \\
\hline Selecky (2001) & - & - & - & $\uparrow \ddagger$ & $\mathrm{NC}^{\ddagger}$ \\
\hline Smith (1998) & - & - & - & $\mathrm{NC}$ & $\uparrow$ \\
\hline \multicolumn{6}{|c|}{ Personal database manager } \\
\hline Cherry (2002) & $\downarrow$ & $\downarrow *$ & - & - & - \\
\hline
\end{tabular}

* Decline indicated a favorable outcome.

${ }^{\dagger}$ No control-two time periods compared.

${ }^{\ddagger}$ No formal test of significance performed.

Internet interventions did not evaluate health care utilization.

$\uparrow$, increase in visits/exams; $\downarrow$, decrease in visits/exams; NC, no change; no HCU outcomes reported; n, \# of studies.

device (i.e., health buddy technology) implemented for daily collection of information from participants. This service allowed the provider to identify problems and intervene before a crisis occurred, which is believed to have resulted in a desired decrease of visits. ${ }^{9}$ Another study decreased clinic visits 2 -fold by using an electronic case manager (ECM) system to facilitate management of glycemic control. ${ }^{19}$ One of the 4 interventions evaluating the number of eye exams performed ${ }^{7,15,24,26}$ produced significant increases. Health care utilization was not evaluated by interventions in the internet category, and studies in the telephone category found no change in hospitalizations and eye exams, mixed results with regard to foot exams, and favorable results in terms of primary care visits. Lastly, the computer-assisted integration of clinical information interventions showed a decline in hospitalizations, favorable outcomes for primary care visits, foot exams, and HbAlc tests, and mixed results in eye exams.

\section{Costs}

Costs associated with the interventions were reported by 9 studies (Table 3) ${ }^{9,11,15-17,19,26-28}$; most authors did not report itemized costs. The majority of the articles reported the costs of the systems used to conduct the interventions, which ranged from $\$ 5.00$ per patient to $\$ 6,340$ for the complete system (i.e., computer, PDA, telemedicine, etc.). Lastly, none of the studies from the internet category, 4 of the 7 studies in the telephone category, ${ }^{11,15,16,19}$ and 5 of the 14 studies in the computerassisted integration of clinical information category reported costs associated with the interventions. ${ }^{9,17,26-28}$

\section{Other Outcomes}

The studies that evaluated behaviors generally found better postintervention self-reporting and documentation of diabetic

Table 3. Costs Associated with the IT Interventions, $n=9$

\begin{tabular}{|c|c|c|c|}
\hline Article Category/First Author, y & Sample Size & Study Duration (mo) & Intervention Cost \\
\hline \multicolumn{4}{|l|}{ Telephone } \\
\hline \multicolumn{4}{|l|}{ Automated calls } \\
\hline Albisser (1996) & 204 & 12 & $\begin{array}{l}\text { \$0.24 (telephone line), \$0.32 to \$0.64 } \\
\text { (postage), and \$5.00 (system) [per patient] }\end{array}$ \\
\hline Meneghini (1998) & 184 & 12 & $\$ 1,000$ per month (system) \\
\hline Piette (2001) & 272 & 12 & \$15 to 25 (cost of study, PPPY) \\
\hline \multicolumn{4}{|l|}{ Telemedicine } \\
\hline Izquierdo (2003) & 46 & 3 & $\begin{array}{l}\text { \$5,078 (system), \$6,340 (system) (2 locations), } \\
\text { \$37 (monthly ISDN line charge), \$14 per } \\
\text { hour (telephone use) }\end{array}$ \\
\hline \multicolumn{4}{|c|}{$\begin{array}{l}\text { Computer-assisted integration of clinical } \\
\text { information } \\
\text { Computer assisted learning }\end{array}$} \\
\hline Albisser (2001) & 978 & 12 & $\$ 1.31$ (cost of study/member/month) \\
\hline Farrant (1984) & 92 & NR & $£ 4,000$ (system) \\
\hline Wise (1986) & 174 & 6 & $\$ 5,000$ (system)—reduced to $\$ 800$ \\
\hline \multicolumn{4}{|c|}{ Electronic disease management systems } \\
\hline Selecky (2001) & 6,469 & 12 & Savings of 5\% (PPPY) \\
\hline \multicolumn{4}{|l|}{ Personal database manager } \\
\hline Cherry (2002) & 169 & 12 & Savings of \$747 (PPPY) \\
\hline
\end{tabular}

Internet interventions did not evaluate costs.

$N R$, not reported; PPPY, per patient per year; mthly, monthly; $£$, pounds. 
crises, moderate use of interventions, and high rates of completion after the intervention. ${ }^{7,9-16,18,19,21,23,25,26,28-32}$ Studies that measured attitudes produced an overall increase in patients' satisfaction with the interventions, personal health care, perceived support, and quality of life. ${ }^{7,9-11,13-15,20,25,26,28,31,33}$ Several studies $(n=8)$ assessing knowledge found an overall increase in patients' understanding of their medical condition. ${ }^{9,14,15,18,22,27,28,30}$ Furthermore, studies $(n=4)$ evaluating patient skills reported that the interventions were easy to use and understand, which typically resulted in short instruction time $\mathrm{e}^{9,18,30,32}$ (data not shown).

\section{DISCUSSION}

The results of this review add to the growing body of evidence that emerging IT may assist with improving health outcomes related to diabetes. Information technology appears to be a developing tool to improve the process of care for type 2 diabetes patients, as indicated by the significant improvements in health care utilization. Nonetheless, there were mixed results regarding declines in $\mathrm{HbAlc}$ levels and the other clinical outcomes (i.e., lipids). Although these findings are consistent with the reviews in type 1 diabetes in terms of psychological and biological outcomes, ${ }^{6}$ a formal metaanalysis conducted by Montani et al., ${ }^{34}$ which also focused mainly on type 1 diabetes, supports the hypothesis that computer-based systems can effectively improve metabolic control.

By mode of delivery, internet interventions had a positive impact on patient-centered outcomes, but generally did not evaluate health care utilization and clinical outcomes. Telephone interventions had a positive impact on primary care visits. Computer-assisted integration of clinical management had a positive effect on most of the health care utilization outcomes. Although several interventions produced large declines in HbAlc, there was no clear pattern by mode and many studies reported no significant change in HbAlc.

The results of this study should be interpreted with several limitations in mind. First, only published studies were reviewed; this introduces the possibility of a publication bias. Second, the heterogeneity of the studies weakened any general inferences and prevented a metaanalysis, which could have allowed for a more quantitative assessment. Finally, only articles written in the English language were reviewed. However, broad inclusion/exclusion criteria were used to increase the likelihood of capturing relevant studies, including a hand search of Diabetes Care and a related articles search for completeness. Furthermore, double review was conducted to minimize errors and increase accuracy in data abstraction. Finally, to our knowledge, this is the first IT review to address type 2 diabetes specifically.

A recent review conducted by Farmer et al. ${ }^{35}$ evaluated the feasibility, acceptability, and effectiveness of telemedicine used to support blood glucose self-monitoring via transmission of results through a remote server, with automated or clinician feedback. Results showed that telemedicine was deemed feasible and acceptable, but evidence for its effectiveness in improving diabetes management was not considered robust. Although the review's primary focus and inclusion/exclusion criteria led to a pool of studies that differed from this review, the results are consistent with our findings related to telemedicine interventions and HbAlc.
This review provides several implications for future research in IT use in diabetes. First, there needs to be improvement in the quality of studies and reporting of results. Based on this review, we strongly recommend that future studies (1) favor RCT designs that enable comparisons with a concomitant control group with less biased assessment of the effectiveness of these interventions; (2) study the long-term ( $>1$ year) effects of these interventions; (3) address and report on the costs associated with the intervention and the resulting cost-effectiveness; and (4) include representative numbers of ethnic minorities and underserved populations and determine whether these interventions are equally effective in these groups. Second, studies should consider participants' perceptions of IT as diabetes self-management as IT will likely remain an integral component of care that depends on the acceptance of the patient. In addition, internet-assisted interventions, which generally focused on patient education, should evaluate $\mathrm{HbAlc}$, health care utilization, and costs associated with the intervention.

Overall, financial support for further research in this area seems promising as the studies in this review were funded by a number of sources including: the National Institutes of Health, National Library of Medicine, professional organizations, and private foundations.

In conclusion, our review suggests that computer-assisted interactive IT could be an important tool and should be evaluated more closely for its potential to improve diabetes care.

The project was funded by several grants from the National Institutes of Health. Dr. Gary was funded by a grant from the NIDDK (UO1-DK57149-05S1); Dr. Brancati was funded by a grant from the NIDDK (K24-DK6222-01); and Ms. Jackson was funded by a grant from the NIGMS (R25GM64124).

\section{REFERENCES}

1. Dagogo-Jack S. Preventing diabetes-related morbidity and mortality in the primary care setting. J Natl Med Assoc. 2002;94:549-60.

2. Lewis $\mathbf{D}$. The internet as a resource for healthcare information. Diabetes Educ. 1998;24:627-30, 632.

3. Eldar R. Health technology: challenge to public health. Croat Med J. 2002;43:470-4.

4. Balas EA, Boren SA, Griffing G. Computerized management of diabetes: a synthesis of controlled trials. Proc AMIA Symp. 1998;295-9.

5. Balas EA, Krishna S, Kretschmer RA, Cheek TR, Lobach DF, Boren SA. Computerized knowledge management in diabetes care. Med Care. 2004;42:610-21.

6. Glasgow RE, Bull SS. Making a difference with interactive technology: considerations in using and evaluating computerized aids for diabetes self-management education. Diabetes Spectrum. 2001;14:99-106.

7. Piette JD, Weinberger M, McPhee SJ, Mah CA, Kraemer FB, Crapo LM. Do automated calls with nurse follow-up improve self-care and glycemic control among vulnerable patients with diabetes? Am J Med. 2000; 108:20-7.

8. Piette JD, Weinberger M, McPhee SJ. The effect of automated calls with telephone nurse follow-up on patient-centered outcomes of diabetes care: a randomized, controlled trial. Med Care. 2000;38:218-30.

9. Cherry JC, Moffatt TP, Rodriguez C, Dryden K. Diabetes disease management program for an indigent population empowered by telemedicine technology. Diabetes Technol Ther. 2002;4:783-91.

10. Glasgow RE, Toobert DJ. Brief, computer-assisted diabetes dietary selfmanagement counseling: effects on behavior, physiologic outcomes, and quality of life. Med Care. 2000;38:1,062-73.

11. Izquierdo RE, Knudson PE, Meyer S, Kearns J, Platz-Synden R, Weinstock RS. A comparison of diabetes education administered through telemedicine versus in person. Diabetes Care. 2003;26:1,002-7. 
12. Levetan CS, Dawn KR, Robbins DC, Ratner RE. Impact of computergenerated personalized goals on $\mathrm{HbA}(1 \mathrm{c})$. Diabetes Care. 2002;25:2-8.

13. McKay HG, King D, Eakin EG, Seeley JR, Glasgow RE. The diabetes network internet-based physical activity intervention: a randomized pilot study. Diabetes Care. 2001;24:1,328-34.

14. Piette JD, Mah CA. The feasibility of automated voice messaging as an adjunct to diabetes outpatient care. Diabetes Care. 1997;20:15-21

15. Piette JD, Weinberger M, Kraemer FB, McPhee SJ. Impact of automated calls with nurse follow-up on diabetes treatment outcomes in a department of veterans affairs health care system: a randomized controlled trial. Diabetes Care. 2001;24:202-8.

16. Albisser AM, Harris RI, Sakkal S, Parson ID, Chao SC. Diabetes intervention in the information age. Med Inform (London). 1996;27:297-316.

17. Albisser AM, Harris RI, Albisser JB, Sperlich M. The impact of initiatives in education, self-management training, and computer-assisted self-care on outcomes in diabetes disease management. Diabetes Technol Ther. 2001;3:571-9

18. Lo R, Lo B, Wells E, Chard M, Hathaway J. The development and evaluation of a computer-aided diabetes education program. Aust J Adv Nurs. 1996;13:19-27.

19. Meneghini LF, Albisser AM, Goldberg RB, Mintz DH. An electronic case manager for diabetes control. Diabetes Care. 1998;21:591-6.

20. Whitlock WL, Brown A, Moore $\mathbf{K}$, et al. Telemedicine improved diabetic management. Mil Med. 2000;165:579-84.

21. Glasgow RE, Boles SM, McKay HG, Feil EG, Barrera M Jr. The D-Net diabetes self-management program: long-term implementation, outcomes, and generalization results. Prev Med. 2003;36:410-9.

22. Wheeler LA, Wheeler ML, Ours P, Swider C. Evaluation of computerbased diet education in persons with diabetes mellitus and limited educational background. Diabetes Care. 1985;8:537-44.

23. Montori VM, Dinneen SF, Gorman CA, Zimmerman BR, Rizza RA, Bjornsen SS. The impact of planned care and a diabetes electronic management system on community-based diabetes care: the Mayo Health System Diabetes Translation Project. Diabetes Care. 2002;25:1,952-7.

24. Smith SA, Murphy ME, Huschka TR, Dinneen SF, Gorman CA, Zimmerman BR. Impact of a diabetes electronic management system on the care of patients seen in a subspecialty diabetes clinic. Diabetes Care. 1998;21:972-6.

25. Glasgow RE, Toobert DJ, Hampson SE. Effects of a brief office-based intervention to facilitate diabetes dietary self-management. Diabetes Care. 1996; 19:835-42.

26. Selecky C. Integrating technology and interventions in the management of diabetes. Dis ManageHealth Outcomes. 2001;9:39-52.

27. Wise PH, Dowlatshahi DC, Farrant S, Fromson S, Meadows KA. Effect of computer-based learning on diabetes knowledge and control. Diabetes Care. 1986;9:504-8.

28. Farrant S, Dowlatshahi D, Ellwood-Russell M, Wise PH. Computer based learnng and assessment for diabetic patients. Diabetic Med: j Br Diabetic Assoc. 1984;1:309-15.

29. Lobach DF, Hammond WE. Development and evaluation of a computerassisted management protocol (CAMP): improved compliance with care guidelines for diabetes mellitus. Proc Annu Symp Comput Appl Med Care. 1994;787-91.

30. McKay HG, Feil EG, Glasgow RE, Brown JE. Feasibility and use of an Internet support service for diabetes self-management. Diabetes Educ. 1998;24:174-9.

31. Rushakoff RJ, Woeber KA. Evaluation of a "formal" endocrinology curbside consultation service: advice by means of internet, fax, and telephone. Endocr. Pract. 2003;9:124-7.

32. Trikic A. Evolving open learning environments using hypermedia technology Evolving open learning environments using hypermedia technology. J Comput Assisted Learning. 2001;17:186-9.

33. Barrera M Jr., Glasgow RE, McKay HG, Boles SM, Feil EG. Do Internetbased support interventions change perceptions of social support?: an experimental trial of approaches for supporting diabetes self-management. Am J Community Psychol. 2002;30:637-54.

34. Montani S, Bellazzi R, Quaglini S, d'Annunzio G. Meta-analysis of the effect of the use of computer-based systems on the metabolic control of patients with diabetes mellitus. Diabetes Technol Ther. 2001;3:347-56.

35. Farmer A, Gibson OJ, Tarasenko L, Neil A. A systematic review of telemedicine interventions to support blood glucose self-monitoring in diabetes. Diabet Med. 2005;1-7. 